\title{
ISLAM DAN PERADABAN
}

\author{
Mukhamad Anieg \\ STIQ Islamic Centre Demak \\ ahlan042000@yahoo.com
}

The word Civilization is often given the same meaning with culture. But there is a difference in meaning between the two terms. The term Civilization to civilization and Culture for culture. Similarly differentiated between in Arabic word Tsaqafah (culture), said Hadharah (progress), and of the Tamaddun (civilization). Al-kala'i argues that culture in the Arabic language means al-tsaqofah.Initially, i.e. from the time of Rosululloh until the 12th century ad this civilization has managed successfully so that it can give birth to world-class historians so that from here can also give birth to community organizations, the economic centre of the region, language, education, religious belief and science, all of which were based on the religion of islam. Already quite a lot of Americans, Europeans and others converted to Islam. However, unfortunately the addition of Muslims is not coupled the readiness concept in Islamic civilization progress. at this time the quantity of people the most is the religion of Islam which reached 1.4 billion people. But it is not the completion of the Muslims in the face of the progress of civilization. Finally the triumph of Islam was down. Therefore, we must build the Islamic Civilization.

Keyword: Civilization, religious, community. 


\section{A. Pendahuluan}

Pada mulanya yaitu dari zaman Rasulullah sampai abad $12 \mathrm{M}$ peradaban ini telah berhasil dengan gemilang sehingga dapat melahirkan para sejarawan kelas dunia sehingga dari sini dapat melahirkan juga organisasi masyarakat, bahasa wilayah, pusat ekonomi, pendidikan, kepercayaan beragama serta ilmu pengetahuan yang semuanya itu berlandaskan atas agama islam.

Sejarah Islam tentu banyak sekali mengandung peristiwa-peristiwa, kejadian-kejadian yang merupakan tamsil/contoh pelajaran bagi kita semua untuk bisa belajar dari setiap peristiwa tersebut, baik peristiwa yang positif, membawa kebaikan bagi perjalanan sejarah Islam maupun peristiwa yang negatif yang membawa keburukan bagi sejarah Islam. Peristiwa yang positif adalah peristiwa yang patut ditiru dan dikembangkan serta dibuat teori-teorinya, sedangkan yang negatif kita berusaha untuk tidak mengulang.

Mempelajari Sejarah Islam adalah bertujuan untuk mempelajari dan mengambil hikmahhikmah dari segala sesuatu yang pernah terjadi dimasa lalu. Sebab, yang namanya sejarah, termasuk sejalah Islam dan umatnya berjalan secara Lineir, seperti garis lurus. Yakni segala sesuatu yang pernah terjadi dimasa lalu tidak mungkin terulangi kembali untuk masa sekarang atau bahkan untuk masa yang akan datang. Karena, berbicara sejarah adalah berbicara tentang masa lalu yang terikat dengan waktu.

Dipermukaan bumi ini kita sering melihat wujudnya peradaban yang timbul tenggelam, begitulah manusia senantiasa tidak tetap yaitu antara bangkit dan jatuh, naik dan turun bahkan jalan ditempat (side ways). Bahkan bangsa-bangsa yang tadinya begitu jaya dan besar lambat laun menjadi kecil dan akhirnya lenyap sehingga di gantikan oleh bangsa yang baru. Dengan pengalaman itu manusiapun dapat mengambil sebuah pengalaman bahwa dirinya harus menerima kemajuan dunia (dinamis) disegala bidang baik kepercayaan beragama, ilmu pengetahuan, peradaban, maupun politik. Jadi tidak sampai 100 tahun islam telah mampu menegakkan dan memperbahurui serta meluruskan faham agama yang telah lalu, ilmu pengetahuan, politik, dan juga peradaban yang selalu berkembang dari satu waktu ke waktu.

\section{B. Pengertian Peradaban Islam}

Kata Peradaban seringkali diberi arti yang sama dengan kebudayaan. Tetapi dalam Bahasa Inggris terdapat perbedaan pengertian antara kedua istilah tersebut. Istilah Civilization untuk peradaban dan Culture untuk kebudayaan. Demikian pula dalam Bahasa Arab dibedakan antara kata Tsaqafah (kebudayaan), kata Hadharah (kemajuan), dan Tamaddun (peradaban). Al-kala'i berpendapat bahwa kebudayaan dalam bahasa arabnya berarti al-tsaqofah. ${ }^{1}$

Menurut A.A. Fyzee, peradaban (civilization) dapat diartikan dalam hubungannya dengan kewarganegaraan karena berasal dari kata civies (Latin) atau civil (Inggris) yang berarti seorang warganegara yang berkemajuan. Dalam hal ini peradaban diartikan dalam dua cara: (1) proses menjadi berperadaban, dan (2) suatu masyarakat manusia yang sudah berkembang atau maju. Adapun kebudayaan diartikan bersifat sosiologis di satu sisi dan antropologis di sisi lain. Istilah 
kebudayan (culture) pada dasarnya diartikan sebagai cara mengerjakan tanah, memelihara tumbuh2an, diartikan pula melatih jiwa dan raga manusia. Dalam latihan ini memerlukan proses dan mengembangkan cipta, karsa, dan rasa manusia. Maka culture adalah civilization dalam arti perkembangan jiwa.

Pendapat Effat al Syarqawi yang mengatakan bahwa kebudayaan adalah bentuk ungkapan tentang semangat mendalam suatu masyarakat. Sedang manifestasi-manifestasi kemajuan mekanis dan teknologi lebih berkaitan dengan peradaban. Jadi kalau budaya lebih di refleksikan dengan seni, sastra, religi (agama) dan moral, maka peradaban direfleksikan dalam bentuk politik, ekonomi, dan tehnologi. ${ }^{2}$

\section{Alhadharah menurut Ibnu Khaldun (ahwalun zaidatun ala dhoruri min ahwalil amran)}

Yaitu: keadaan yang berlebih-lebihan yang dibutuhkan oleh kondisi sebuah bangunan. Atau dengan kata lain kemewahan hidup. Dan itu tampak di kota dan perkampungan, dan tidak tampak di padang belantara, oleh karena itu kata hadharah kebalikan dari kata badwin (padang belantara) ${ }^{3}$

Sedangkan Nuruzaman Shidiqi mengutip dari A.J Wensink menolak bahwa culture (kebudayaan) dan civilization (peradaban) adalah dua kata dalam satu makna. Menurut dia kebudayaan lebih luas artinya daripada peradaban. Sebab kebudayaan adalah akal budi manusia yang bersifat bathiniyah. Akal budilah yang mendorong manusia untuk menciptakan kesusteraan, kesenian, dan sebagainya dalam rangka mencapai kehidupan manusia yang lebih baik.

Oleh karena itulah kebudayaan adalah salah satu yang memimpin manusia dalam kehidupan dilingkungan agama, filsafat, politik, ekonomi, sosial, ilmu pengetahuan, susila dan sebagainya. Sedangkan peradaban adalah hasil pengolahan akal budi dalam bentuk lahiriyah. Contohnya : kemampuan membangun bangunan pencakar langit, mengirim satelit keruang angkasa dsb. ${ }^{4}$

Sedangkan pensifatan "Islam” terhadap kata peradaban menunjukkan bahwa peradaban itu berasal dari orang-orang yang memeluk agama Islam dan berada di bawah pemerintahan islam sehingga didalamnya termasuk pula orang orang Nasrani,Yahudi, Majusi dan Syabi ah. ${ }^{5}$

Dari uraian di atas dapat disimpulkan bahwa peradaban islam adalah manifestasi-manifestasi kemajuan manusia dibidang lahiriyah yang berupa teknologi, poitik, ekonomi yang muncul dari kaum muslimin di masa pemerintahan islam.

\section{Ciri - Ciri Dan Karakteristis Peradaban Islam}

Kita tahu bahwa Jahiliyah tidak menjelma di dalam bentuk teori saja. Ia menjelma dalam bentuk organisasi, dalam bentuk masyarakat dan perkumpulan yang tunduk kepada kemauan dan arahan masyarakat itu, tunduk kepada kehendak konsep, nilai-nilai dan faham, perasaan dan kebiasaan. Ia merupakan masyarakat yang terikat kuat, tersusun, setia, rapi, padu dan

\footnotetext{
2 Effat Al-Sarqowi, Filsafat Kebuyaan Islam, (Bandung, Pustaka , 1986), hlm. 5

3 Ibid: hlm. 11

4 Nuruzaman shidiqi, Tamaddun Muslim, (Jakarta, Bulan Bintang, 1986), cet ke 1 hlm : 2

5 Abd al Mun'in Majid, Tarikh al-khadloroh al-Islamiyah, Cairo, 1978, cet ke-4, hlm. 11
} 
tak mungkin direnggangkan. Inilah yang menyebabkan masyarakat itu bergerak, secara sadar atau tak sadar, untuk mengekalkan wujudnya dan mempertahankan hayatnya, menentang dan menghancurkan semua unsur yang membahayakan wujud dan hidupnya dalam bentuk ancaman apa pun.

Karena jahiliyah itu tidak berupa "teori” saja melainkan juga berupa organisasi, maka usaha menghapus jahiliyah itu dan membawa manusia ke jalan Allah sekali lagi harus tidak terbatas dalam soal "teori" saja, karena cara yang demikian tidak akan mempan menghadapi jahiliyah yang telah berakar dan telah lama membumi di dalam masyarakat.

Mereka akan bergerak dan bertindak, baik sadar atau tidak, untuk menunaikan kehendak masyarakat jahiliyah itu. Mereka akan ikut mempertahankan hidupnya, mereka juga akan ikut serta menghalangi semua tujuan dan sebab yang bisa mengancam kehidupan masyarakat jahiliyah. Mereka secara otomatis mengikuti jejak anggota masyarakat jahiliyah yang ingin mempertahankan hidupnya dan ingin pula mengekalkan keutuhan masyarakat itu, baik mereka sadari atau tidak, mereka suka atau tidak. Akan tetapi islam bukanlah seperti itu, karena islam mengajarkan kebenaran.

Di dalam masyarakat Islam yang tiada tolok bandingnya itu, telah berkumpul bangsa Arab, Parsi, Syam, Moroko, Mesir, Turkey, China, Roman, Yunani, India, Indonesia, dan juga orang Afrika, malah seluruh bangsa di dunia ini. Mereka bersatu padu dan bekerjasama dengan eratnya dalam membina masyarakat dan peradaban Islam. Peradaban yang agung, yang tidak pernah sekalipun menjadi peradaban yang dimiliki oleh orang ARAB saja, malah ia menjadi peradaban ISLAM; juga tidak menjadi masyarakat kebangsaan dan perkauman, bahkan menjadi masyarakat yang berlandaskan akidah. Mereka semuanya berkumpul berdasarkan hubungan persamaan, hubungan kasih mesra dan persaudaraan, dengan memandang jauh ke depan, ke arah satu tujuan. Mereka memberi apa saja yang dapat mereka berikan, tanpa menghilangkan ciri-ciri kebangsaan mereka.

Di zaman moderen ini pun beberapa bentuk masyarakat telah berdiri dan telah runtuh. Sebagai contoh, kita ambil masyarakat Kekaisaran Inggris (Britain), tapi bentuknya tak beda dengan bentuk kekaisaran Romawi yang diikutinya dahulu itu, yang bertujuan memeras dan menindas, telah tegak berdasarkan ketuhanan bangsa Inggeris dan memeras serta menindas rakyat jajahannya demikianlah juga halnya seluruh kekaisaran Eropa lainnya: kekaisaran Spanyol dan Portugis suatu ketika dahulu, dan juga empire Perancis, semuanya itu sama saja taraf dan nilainya, yang memang semuanya berdasarkan pemerasan dan penindasan yang terkutuk.

Tampaknya, komunisme berhasrat mendirikan perkumpulan dan masyarakat manusia bermodel lain, yang melampaui unsur-unsur kebangsaan dan wama kulit, tanah air dan bangsa, tapi tidak dibangun berdasarkan KEMANUSIAAN malah berlandaskan pertentangan KELAS. Yang demikian, maka masyarakat ciptaan Komunisme itu merupakan masyarakat yang setara dengan masyarakat ciptaan Romawi yang satu berdasarkan tingkatan kaum bangsawan (tuan) dan hamba tapi yang satu lagi ini berdasarkan kekuasaan golongan melarat tertindas (proletaria) dan kaum menengah (borjuis) dan ciri emosi yang membakar semangat masyarakat Komunis 
dan kaum proletariat itu ialah kebencian dan kedengkian terhadap seluruh kelas dan golongan lain.

Masyarakat seburuk ini tidak akan menelurkan hasil apa-apa kecuali mencetuskan gejalagejala yang paling buruk di dalam sejarah umat manusia karena dari asal kelahirannya, ia menonjolkan ciri-ciri dan sifat hewan dengan beranggapan bahwa keperluan-keperluan asasi bagi manusia itu ialah makan, minum, rumah tangga dan seks, yang semuanya ini adalah tuntutan dan keperluan asasi hewan, dengan anggapan bahwa sejarah umat manusia ini dimulai dengan sejarah mencari makan.

Di antara keindahan Islam itu bahwa islam tetap bersendirian dan masih tegak di atas panduan Ilahi dengan cara menonjolkan sifat dan ciri-ciri khusus manusia dan mengangkat nilai-nilai kemanusiaan yang begitu tinggi di dalam membentuk masyarakat manusia. Dan sudah pasti Islam akan terus bersendirian di dalam hal ini dan siapa saja yang mencoba menyeleweng ke arah panduan yang lain, menegakkan suatu jalan yang lain, apakah jalan kebangsaan, warna kulit, tempat kelahiran dan kelas, atau jalan-jalan lain yang rendah dan hina, maka orang itu adalah musuh manusia yang jelas.

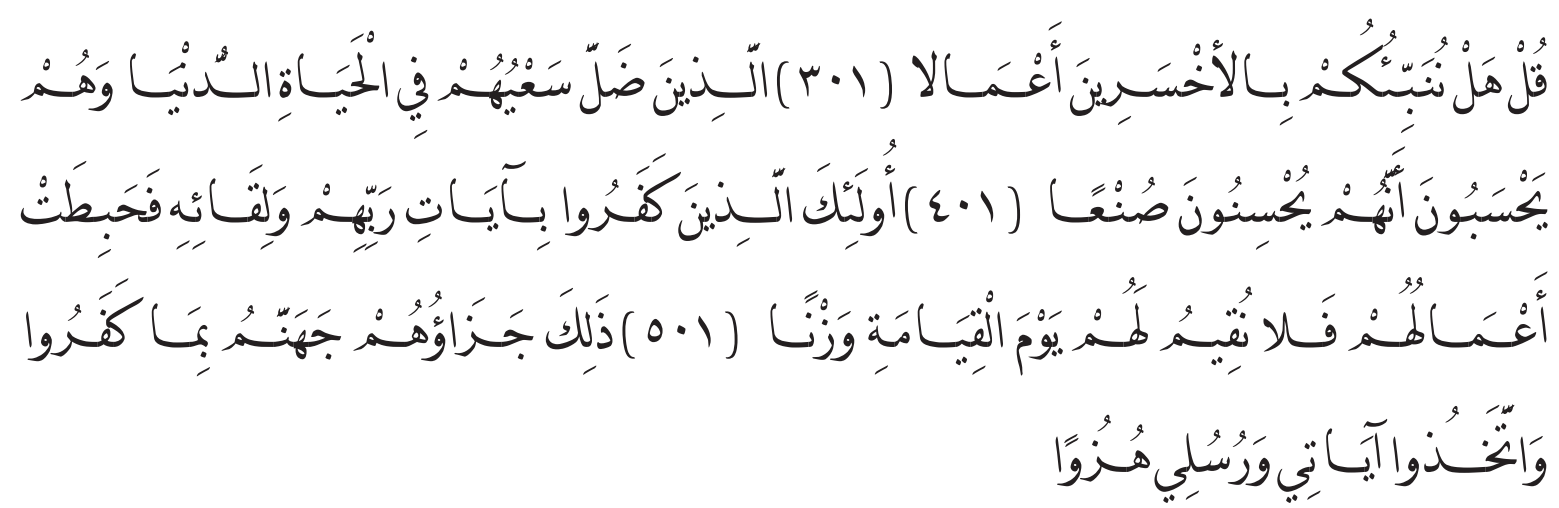

"Katakanlah maukah aku beritahu kepada kamu tentang orang yang paling rugi perbuatan-perbuatan mereka, orang-orang yang sia-sia amal perbuatan mereka di dalam hidup dunia ini sedangkan mereka itu menyangka bahwa mereka sebenarnya berbuat baik. Mereka itu ialah orang-orang yang kufur dan tidak bersyukur dan tidak percaya dengan perintah Tuhan mereka dan tidak percaya bahwa mereka akan menghadap Tuhan mereka itu lalu pekerjaan mereka pun menjadi hampa dan Kami tidak berikan pertimbangan dan penilaian apa pun kepada mereka di hari kiamat. Balasan mereka ialah neraka Jahannam karena kekufuran mereka dan karena mereka memperolok-olokkan perintah-perintahKu dan juga rasul-rasul utusanKu" (Al Kahfi: 103-106)

Jadi secara mendasar kita dapat melihat kerakteristik peradaban islam yaitu ada dua macam, yaitu:

1. Bernafaskan tahuhid, karena tauhid lah yang menjadi perinsip pokok ajaran Islam. ${ }^{6}$

2. Hasil buah pikir dan pengolahannya adalah di maksudkan untuk meningkatkan kesejahteraan dan kebahagiaan umat manusia. Sebab, Islam diturunkan dan Nabi diutus adalah untuk

6 G.E Von Grunebaum, Islam Essays in the Nature and Growth Of Cultural Tradition, London: Routledge \& Kegal Paul Ltd, 1979. hlm 
membawa rahmat bagi alam. Disamping itu juga manusia di jadikan sebagai kholifah Allah dibumi dengan dibebani tugas untuk menjaga keindahan ciptaan Allah ini. Allah berfirman, janganlah engkau membuat kerusakan di bumi, Oleh karena itu produk peradaban yang membawa kerusakan dan kehancuran, seperti perlombaan persenjataan jelas tidak termasuk peradaban yang bercirikan islam.?

Dari sisi perkembangannya dapat kita simpulkan bahwa masyarakatnya memeiliki ciri - ciri yaitu:

1. Orang - orangnya suka membuat perkotaan baru dan membangunnya.

2. Berusaha membuat sistem pemerintahan yang baik dan dinamis.

3. Selalu berusaha membuka lapangan pekerjaan di segala bidang.

4. Selalu ingin melaksanakan kegiatan - kegiatan keagamaan sesui dengan kepercayaan yang di yaqininya.

5. Dari perkembangannya mereka memiliki media pengantar baik yang berupa tulisan, simbul dan sebagainya. ${ }^{8}$

Menurut Lew Hee Men, ciri - cirinya adalah :

1. Adanya kota dan pelabuhan.

2. Adanya tulisan dan bahasa

3. Adanya organisasi sosial.

4. Technologi berkembang maju.

5. Agama yang kuat mempengaruhi kehidupan masayarakat.

6. Kerajaan dan sistem pemerintahan yang berkuasa muncul.

7. Ada suatu bentuk-bentuk tulisan. ${ }^{9}$

Demikianlah beberapa hal mengenai ciri dan karakteristik peradaban islam yang menjadikannya istimewa di antara peradaban lainnya didunia, sebagai salah satu bentuk rahmat yang dibawa oleh risalah Islamiyah kepada seluruh alam.

\section{Visi Islam Sebagai Agama Peradaban}

Islam sebagai agama merupakan wahdun ilahiyun yang berarti peraturan dari Allah Yang Maha Tahu dan Maha Kuasa yang kebenarannya mutlak dan abadi. Peraturan Allah Swt. Itu telah tertuang dalam Al-Quran yang diwahyukan kepada nabi Muhammad selama 23 tahun. Sebagi pediman hidup, Alquran sudah mencakup seluruh aspek kehidupan dan sebagai kerangka operasionalnya, Nabi Muhammad Saw. telah menerjemahkannya dalam bentuk ucapan, perbuatan serta ketetapannya yang disebut dengan istilah Hadits atau Sunah. Dengan demikian, Al qurna dan Sunah Nabi merupakan sumber ajaran islam yang harus dipahami secara dinamis sehingga dapat dijadikan sebagai pedoman kehidupan sepanjang zaman dalam semua hal.

Sejak adanya manusia, Allah telah menetapkan aturan tatacara beribadah dan bermuamalah

7 Nuruzaman Shidiqi Tamaddun Muslim, Jakarta, Bulan Bintang, cet ke - 1, 1986 hlm. 1

8 Nigel Kelly dan Goh Phay Yen, 1992, hlm. 37

9 Lew HeeMen, Sejarah Peradaban Islam, (Jakarta, CV.Ananda, 2000), hlm. 4 
yang mengikat manusia. Sebagai agama samawi, Islam merupakan agama yang telah didakwahkan oleh nabi-nabi dan Rosul-Nya sebelum Nabi Muhammad Saw.

Sebagai aturan Allah, dalam waktu yang relatif singkat islam telah menghapuskan perbagai kemusyrikan yang berkembang pesat dikalangan bangsa Arab dan sekitarnya, kemudian menggantikannya dengan tauhid dan panji-panji perdaban islam yang bersendikan nilai-nilai aqidah, syariah, dan akhlaq. Sebagian dari buahnya adalah semangat amar máruf nahi munkar, ukhuwah islamiyah, solidaritas dan persamaan, serta toleransi dan kerukunan dengan penganut agama lain.

Oleh karena itu, umat islam dapat hidup berdampingan dan bekerja sama dengan penganut agama lain dalam berbagai bidang menciptakan kemaslahatan dan memenuhi hajat hidup bersama. Rasul telah memberikan contoh kongkrit dalam menangani persoalan kehidupan bersama baik dalam hal ekonomi, sosial, maupun politik dengan melakukan kerjasama dengan mereka (non muslim), tetapi tentunya dalam batas-batas yang bisa menyelamatkan dan mensejahterakan bersama. Oleh karena itu, secara politis sekarang ini, interdependensi antara negara Barat dan Timur, antara negara maju dan berkembang, antara negara produsen dan konsumen yang telah terjamin hubungan bilateral, tidak hanya akan memberikan keuntungan ekonomi dan akulturasi budaya, melainkan juga akan mempengaruhi perinsip moral. Hal ini menuntut kemampuan para praktisi muslim untuk mengusahakan suatu usaha rekayasa yang dapat mengangkat peradaban islam ke permukaan sehingga dapat kembali mewarnai peradaban dunia, tidak terjebak dalam perangkap mereka. Dengan demikian, kesejahteraan bisa dirasakan dan dijalankan bersama-sama.

Peradaban Islam mempunyai toleransi keagamaan yang mengagumkan yang tidak pernah dikenal oleh peradaban lain yang juga berpijak kepada agama. Pemeluk agama yang meyakini bahwa agamanya benar dan akidahnya paling lurus dan sah, kemudian ia diberi kesempatan untuk memanggul senjata, menaklukkan kota-kota, menguasai pemerintahan dan menduduki kursi pengadilan dan kesempatan itu tidak membuatnya lalim atau menyimpang dari garis-garis keadilan atau tidak menjadikan dia memaksa untuk mengikuti agamanya, maka orang semacam ini sungguh aneh ada dalam sejarah. ${ }^{10}$

Jadi, sebagai agama islam mampu mengatur manusia dengan konsep akidah yang menjadi landasan syariah dan akhlaq yang di aplikasikan dalam kehidupan sehari-hari, baik dalam beribadah maupun dalam menciptakan karya budaya. Sehingga dalam bermuamalah yang lebih luas misalnya, umat terikat dengan nilai-nilai akidah, syariah dan akhlaq dalam pengertian yang seluas-luasnya, agar dapat melahirkan wujud peradaban yang bisa menegakkan sendi-sendi iman,islam dan ihsanmenuju terciptanya baldatun toyibatun warobun ghofur. Merka akan saling mempengaruhi antara sistem dan pelaku sejarahnya serta produk budaya atau perdaban yang dihasilkannya.

10 Mustafa Saba'i, Some Glittering Aspects of the Islamic Civilization, Translation Sharif Ahmad Khan, (Delhi, 1982), hlm. 30-34. 


\section{E. Jatuh Bangunnya Peradaban Islam Dan Kiatnya Menghadapi Peradaban Barat}

Dalam catatan sejarah, pernah dituliskan dengan tinta emas adanya puncak kemajuan kebudayaan Islam, terutama pada pemerintahan "khalifah al-Ma'mun" dari dinasti Abbasiyah, yang ditandai dengan sistem pemerintahan yang adil, menjamin kebebasan berpikir sehingga pada zaman itu, berdiri pusat-pusat kajian dan penterjemahan buku-buku filsafat Yunani dan berkumpul berbagai ilmuwan dari berbagai kalangan keagamaan, dengan "sistem ekonomi perdagangan yang terbuka”, di mana saat itu, kota Baghdad menjadi kota perdagangan. Akan tetapi setelah pemerintahan al-Ma'mun, tanda-tanda kejatuhan dan kemunduran kebudayaan Islam mulai merebak, yang ditandai oleh ketidakmampuannya dalam menyelenggarakan pemerintahan yang adil, sikap hidup para pemimpin dan orang-orang kaya di sekitarnya yang suka berfoya-foya, serta terjadinya frustrasi akademik di kalangan kaum terpelajar. ${ }^{11}$

Puncak kebudayaan Islam itu tidak dicapai dengan seketika, demikian pula halnya kejatuhannya, proses itu berjalan dalam rentang waktu lama ratus tahun, sejak abad ke tujuh sampai abad ke dua belas masehi. Dalam periode itu, "umat Islam terpukau oleh pemikiran Yunani”, mereka melakukan penterjemahan buku-buku Yunani secara besar-besaran, akan "tetapi mereka mengabaikan fundamental bangunan intelektual" dari akar tradisinya sendiri, yang diwariskan oleh tradisi kenabian. Sri Muhammad Iqbal, melukiskan keadaan itu dengan pernyataannya bahwa mereka membaca Al-Qur'an dengan cahaya pemikiran Yunani, padahal jiwa intelektual yang dibangun oleh al-Qur'an itu bersifat actual, dalam amal kesalehan sebagai jalan spritual, berbeda dengan jiwa intelektual Yunani yang bercorak spekulatif, dan rasional semata-mata. ${ }^{12}$

Di lihat dari konteks metoda berpikir kefilsafatan, barangkali pernyataan adanya "kemajuan kebudayaan" yang disebut dengan kebudayaan Islam itu, sesungguhnya masih bersifat semu saja”, karena sesungguhnya yang ada bukan "kebangkitan kebudayaan Islam”, tetapi kebangkitan kebudayaan Yunani dalam pemerintahan dan masyarakat Islam. Persoalan ini, telah muncul perdebatan akademik dalam pemikiran filsafat dengan sangat serius, apakah filsafat Islam itu pernah ada, karena yang ada adalah bukan filsafat Islam tetapi filsafat Yunani yang diberi baju Islam. ${ }^{13}$

Dalam konsep filsafat Islam, kebudayaan Islam baik pada dataran konsep maupun produk, pada dasarnya harus ditegakkan dan dibangun oleh berfungsinya aqal qudus secara seimbang, baik dalam dimensi pikir maupun zikir, berdasarkan wawasan hikmah dan kitab, sehingga kebudayaan Islam tidak dibangun dan ditegakkan berdasarkan rasio semata-mata, yang akan mengakibatkan kebudayaan kehilangan dimensi spritualitasnya, dan mempunyai kecenderungan terlapas dari wawasan moralitas kemanusiaan universal dan spritual agama.

Oleh karena itu, ketahanan suatu kebudayaan sepenuhnya ditentukan oleh keseimbangan "dealektik antara kreaktifitas" dan wawasan moralitas, yang secara seimbang menjadi manifestasi aktual dan dinamis dari keseimbangan "iman" dan "ilmu" dalam tindakan amal kesalehan. Pada

11 Musa Asy'ari, 1999, Filsafat Islam tentang Kebudayaan, LESFI, Yogyakarta, hlm, 79.

$12 \mathrm{Ibid}$, hlm, 79.

13 Musa Asy’ari, 1999, Op. Cit., hlm, 80. 
dataran ini, kebudayaan menjadi sasaran komunikasi dan dialog kreatif dengan Tuhannya, dalam suatu pertemuan penciptaan yang bermakna.

Ketika daulah Amawiyah, Abasiyah, dan Fatimiyah mengalami kemunduran yang akhirnya runtuh, bangsa barat mulai membangun peradabannya, padahal penyebab kemajuan dunia Barat itu berkat mengkaji kebudayaan muslim dengan datang belajar kepada kaum muslimin baik ke Baghdad maupun Spanyol. Buku-buku yang berbahasa arab dalam berbagai disiplin ilmu disalin ke bahasa latin. ${ }^{14}$ Akhirnya peradaban barat maju pesat dan sekarang mendominasi peradaban dunia sedangkan peradaban kaum muslimin tenggelam bagaikan tidur. Abad ke$15 \mathrm{H}$ didengungkan oleh kaum muslimin sedunia sebagai abad kebangkitan kaum kuslimin sehingga diharapkan peradaban Islam yang tengah tidur itu dapat juga bangun kembali mengisi percaturan peradaban dunia.

Dalam peradaban barat prinsip-prinsip iman dikesampingkan, azaz moral dan akhak diacuhkan, nilai kemanusiaan dalam setiap perbuatannya dirobek-robek, tidak pernah ingat kepada Allah; maka orang yang seperti ini hidupnya dikuasai syethan. Manusia-manusia jenis ini kalau menghadapi tantangan zaman, jika berhadapan dengan hal-hal yang tidak cocok dengan hawa nafsu mereka, jika ditimpa oleh kekurangan materi atau kemanusiaan; akan terus menerus hidup dalam kesedihan, hilang pribadi dan panik. Mereka akan selalu mengingkari yang haq, selalu menyalahkan keadaan. Selanjutnya hidupnya dikuasai oleh kepanikan dan ketakutan.

Seiring dengan kemajuan peradaban, umat manusia menghadapi permasalahan kehidupan yang semakin jauh dari nilai-nilai kemanusiaan. Gaya hidup modern yang materialistis telah menciptakan suasana hidup tidak menentu, tujuan hidup yang kosong, lalu diiringi oleh penyakit-penyakit jiwa, dan lain sebagainya.

Apa ciri-ciri pokok peradaban Barat ini? Taqiyuddin an-Nabhani (1953) dalam Nizham al-Islam menerangkan ada 3 (tiga) ciri-ciri pokok peradaban modern, yaitu :

1. Berasaskan sekularisme (pemisahan agama dari kehidupan);

2. Berstandar manfaat (utilitarianisme/pragmatisme) dalam mengukur segala perbuatan manusia;

3. Bersifat hedonis (mementingkan kenimatan fisik) dalam memahami makna kebahagiaan.

Ringkasnya, ciri-ciri pokok peradaban Barat adalah : sekularistis, pragmatis, dan hedonis.

Namun satu hal yang perlu dipahami, peradaban adalah kategori ideologis, bukan kategori geografis. Maka dari itu, peradaban modern, tidak hanya dapat ditemukan di Barat (AS dan Eropa) tapi juga di belahan lain di dunia. Indonesia walaupun mayoritasnya muslim dan bukan bagian AS atau Eropa, namun secara peradaban termasuk pada peradaban Barat. Sebab ciri-ciri pokok peradaban Barat yang tiga tadi (sekularistik, pragmatis, hedonis) terwujud nyata dalam realitas masyarakat Indonesia.

Gagasan Islam sangat berbeda dengan gagasan Barat di dalam menanggulangi masalah manusia. Kalau gagasan barat bersifat materi semata, maka Islam memandang manusia sebagai

14 Nuruzaman Shidiqi, Op. Cit., hlm. 15 
materi dan roh. Segala bentuk penyelesaian yang dikemukakan oleh ahli-ahli filosofi barat selalu berdasarkan perhitungan dan angka-angka, pada percobaan ilimah, pada obat-obat penenang dan perangsang; tanpa memperhatikan segi kerohani-an manusia. Oleh sebab itu, pemikirpemikir barat ini selalu gagal di dalam menanggulangi masalah peradaban. Sebab mereka sejak semula telah salah dalam menentukan diagnosis. Dalam ilmu kedokteran modern ada suatu motto yang mengatakan: "Kalau anda ingin menyembuhkan seorang pasien, pertama-tama anda harus mengetahui sebab penyakitnya; kalau anda telah mengetahui sebab, pengobatan akan menjadi gampang, karena obat tidak lebih dari menghilangkan sebab penyakit". ${ }^{15}$

\section{F. Kesimpulan}

1. Islam mampu mengatur manusia dengan konsep akidah yang menjadi landasan syariah dan akhlaq yang di aplikasikan dalam kehidupan sehari-hari, baik dalam beribadah maupun dalam menciptakan karya budaya. Sehingga dalam bermuamalah yang lebih luas misalnya, umat terikat dengan nilai-nilai akidah, syariah dan akhlaq. Dalam pengertian yang seluasluasnya, agar dapat melahirkan wujud peradaban islam yang bisa menegakkan sendi-sendi iman,islam dan ihsan menuju terciptanya baldatun toyibatun warobun ghofur

2. Bahwa dalam pandangan Islam, sebab-sebab penyakit dan kegoncangan peradaban modern itu tersimpul dalam beberapa faktor yang dapat kita ringkaskan sebagai berikut:
a. Tirani materi.
b. Kekosongan gagasan akidah.
c. Ketiadaan nilai moral dan kesadaran agama.
d. Ketiadaan rasa kasih sayang dalam masyarakat modern.
e. Faktor ekonomi adalah juga sebab utama dari kepanikan.
f. Kebisingan kota yang ditimbulkan oleh sarana-sarana transportasi modern dan komunikasi.

3. Sudah cukup banyak orang Amerika, Eropa dan lainnya memeluk agama Islam. Namun, sayangnya penambahan umat Islam ini tidak dibarengi kesiapan konsep dalam kemajuan peradaban Islam itu sendiri, Terbukti pada saat ini jumlah umat yang paling banyak adalah agama Islam yakni mencapai 1,4 miliar orang. Tetapi tidak siapnya umat Islam dalam menghadapi kemajuan peradaban mengakibatkan kejayaan Islam menurun.Kejayaan Islam tidak seperti jaman dahulu lagi yang memiliki sumber daya keilmuan, teknologi dan lainnya, yang menjadi acuan bagi orang-orang barat.Selain itu, tidak bersatunya umat Islam, antara negara-negara Islam yang ada di dunia juga bisa menjadi penyebab menurunnya kejayaan Islam. 


\section{Bibliografi}

Abd al Mun'in Majid, Tarikh al- khadloroh al-Islamiyah, Cairo, 1978, cet ke-4,

Asad M. Al-Kala'i, Kamus Indonesia Arab, Jakarta, Bulan Bintang, 1995. cet. Ke 6

Dr. Ahmad Syauqi Al-Fanjari, At-Thibb al-Waqaai fi al Islam (terjemahan), Cairo, 1978.

Effat Al-Sarqowi, Filsafat Kebuyaan Islam, Bandung, Pustaka, 1986.

G.E Von Grunebaum, Islam Essays in the Nature and Growth Of Cultural Tradition, London: Routledge \& Kegal Paul Ltd, 1979.

Lew HeeMen, Sejarah Peradaban Islam, Jakarta, CV.Ananda, 2000.

Musa Asy’ari, Filsafat Islam tentang Kebudayaan, Yogyakarta, LESFI, 1999.

Mustafa saba'i, Some Glittering Aspects of the Islamic Civilization, Translation Sharif Ahmad Khan, Delhi, 1982.

Nigel Kelly dan Goh Phay Yen, 1992.

Nuruzaman Shidiqi, Tamaddun Muslim, Jakarta, Bulan Bintang, 1986, cet ke 1 